\title{
The Study of Performance Management System In IT Organizations
}

\author{
Sandeep Gudla ${ }^{1}$, Valli Sri Krishna Veni ${ }^{2}$ \\ ${ }_{1,2}$ (MBA, Vignan Institute of Information Technology, India)
}

\begin{abstract}
The Indian IT sector has also built a strong reputation for its high standards of software development ability, service quality and information security in the foreign market- which has been acknowledged globally and has helped enhance buyer confidence. The role of HR in the present scenario has undergone a sea change and its focus is on evolving such functional strategies which enable successful implementation of the major corporate strategies. Today, HR works towards facilitating and improving the performance of the employees by building a conducive work environment and providing maximum opportunities to the employees for participating in organizational planning and decision making process. The paper discusses about the role of performance management in IT industry.
\end{abstract}

Key words: IT sector, Information security, Performance, Opportunities, Corporate

\subsection{Introduction of Performance Management System:}

\section{Introduction}

Performance management is the current buzzword and is the need in the current times of cut throat competition. Performance management encompasses activities such as joint goal setting, continuous progress review and frequent communication, feedback and coaching for improved performance, implementation of employee development programmes and rewarding achievements. The process of performance management starts with the joining of a new incumbent in a system and ends when an employee quits the organization. Performance management can be regarded as a systematic process by which the overall performance of an organization can be improved by improving the performance of individuals within a team framework. It is a means for promoting superior performance by communicating expectations, defining roles within a required competence framework and establishing achievable benchmarks.

Performance management system can focus on the performance of an organization, a department, employee, or even the processes to build a product or service, as well as many other areas. It includes activities that ensure that goals are consistently being met in an effective and efficient manner. This is used most often in the work places where people will interact. Organizations succeed when they continuously nourish the top performers and improve the poor performers.

Successful organizations know that to win in today's competitive marketplace they must attract, develop, and retain talented and productive employees. Performance management system helps them hire talented people, place them in the right position, align their individual performance with the organization's vision and strategic objectives, develop their abilities, and reward performance commensurate with contributions to the organization's success.

\subsection{Overview of IT Industry:}

Information technology (IT) is defined as the design, development, implementation and management of computer-based information systems, particularly software applications and computer hardware. Today, it has grown to cover most aspects of computing and technology. The reason why it has catapulted in importance is due to the improving accessibility, awareness and utility of technology. It is a common fact that a country's IT potential is paramount for its march towards global competitiveness, healthy GDP and defense capabilities.

The strong demand for electronic hardware and software in India has been fuelled by a variety of drivers including the high growth rate of the economy, emergence of a vast domestic market catering to the new generation of young consumers, a thriving middleclass populace with increasing disposable incomes and a relatively low-cost work force having advanced technical skills. The industry continues its drive to set global benchmarks in quality and information security through a combination of provider and industry-level initiatives and strengthening the overall frameworks, creating greater awareness and facilitating wider adoption of standards and best practices 


\subsection{Performance Management System in IT Industry:}

Armstrong and Baron (1998) defined Performance Management System as a "strategic and integrated approach to increasing the effectiveness of companies by improving the performance of the people who work in them and by developing the capabilities of teams and individual contributors." It may be possible for the goal congruence i.e., reconcile the employee's personal goals with the organizational goals and thereby increase the productivity and profitability of the organization. Managing the employee performance facilitates the effective delivery of strategic and operational goals.

Performance management aims at developing individuals with the required commitment and competencies for working towards the organizational objectives. Performance management frameworks are designed with the objective of improving both the individual and organizational performance by identifying performance requirements, providing regular feedback and assisting the employees in their career development. Its focus is on enabling goal clarity for making people do the right things in the right time. The main goal of performance management is to ensure that the organization as a system and its subsystems work together in an integrated fashion for accomplishing optimum results.

There are certain components for an effective Performance management system. These include performance planning, appraisal and reviewing, feedback on performance, rewarding good performance and performance improvement plans. Performance planning has to be done jointly by the appraise and reviewer in the beginning of a performance session and during this period the employees decide upon the targets and key performance areas. Normally the appraisals are performed twice in a year. In this process, the appraise first offers the self-appraisal forms and then final ratings are provided by the appraiser for the quantifiable and measurable achievements of the employee being appraised.

Feedback and counseling is given a lot of importance in the performance management process. At this stage the employee receives an open and a very transparent feedback and along with this the training and development needs of the employee is also identified. The appraiser adopts all the possible steps to ensure that employee meets the expected outcomes for an organization through effective personal counseling and guidance, mentoring and representing the employee in training programs which develop the competencies and improve the overall productivity. Rewards will be a vital component for work motivation of an employee. An employee is publicly recognized for good performance and is rewarded. Any contribution duly recognized by an organization helps an employee in coping up with the failures successfully and satisfies the need for affection. If the employee shows poor performance then again fresh set of goals are established for that employee and new deadline is provided for accomplishing those objectives. The employee is clearly communicated about the areas in which the employee is expected to improve and a stipulated deadline is also assigned within which the employee must show the improvement. Performance improvement plans are also jointly developed by the appraise and the appraiser and is mutually approved.

The performance management approach has become an indispensable tool in the hands of the corporate as it ensures that the people will uphold the corporate values and tread in the path of accomplishment of the ultimate corporate vision and mission. It is a forward looking process as it involves both the supervisor and also the employee in a process of joint planning and goal setting in the beginning of the year.

\section{Review Of Literature}

Performance management systems are powerful tool for change. They were used in the 1980s and 1990s to try to bring about change in public sector culture and ethos. People in the same job with the same experience expected and got the same pay and had roughly the same prospects of promotion. The shift towards a performance culture was a dramatic one. It was based on equity, rather than equality, and managed by means of performance. Since that meant being rewarded for what the employees did, it also required help and clear feedback on a regular basis from managers on individual performance. It required specific goals and targets to be set, with measurable success criteria such as key performance indicators, or key result areas. It required regular progress reviews and a meaningful annual appraisal. Data had to be collected on performance and that served as the basis for all decision making.

Craig Eric Schneir identified the problems typically encountered when attempting to improve performance, productivity, and quality through implementing performance management system. Organizations develop strategic plans that may call for new products or technologies. These plans must become operational in order to succeed. The goals and the idealized vision are necessary, but rarely sufficient. They must be coupled with a performance management system that identifies what counts, helps measure it and holds people accountable for achieving it. Long run, institutionalized change occurs if key human resource management systems, such as appraisal, reward, selection, and training are affected. There is a weak relationship in many organizations between what is formally stated as important and what is known by employees and managers to count. 
Inconsistencies between performance and compensation are often painfully obvious. A recent study showed that less than one in three companies actually linked top executive rewards to corporate performance. In order to attain lasting change, performance must be identified and measured via performance management and rewarded and recognized via an effective recognition and reward system. A survey has indicated that top management must build the accountability required to allow change to occur. Consequences for performancepositive and negative- must be available. Many organizations have restricted or eliminated across-the-board pay increases. Monetary rewards are often scarce and other rewards are highly valued. With values and expectations, today's work force demands a broad view of rewards.

Victor Y.Hanies(2004) published an article in Canadian Journal of Administrative Sciences. According to him organizations increasingly view performance management as a key system that can promote and sustain initiatives such as speed to market, business performance expectations, feedback, and reward systems to people requirements, performance management may foster employee behaviours that are consistent with emerging business opportunities and the need for strategic and operational effectiveness.

Deming(1986) and Bowman, Scholtes(1994) argue, however, that the practice of performance management, including performance appraisal, is not compatible with the principles of quality management. Their main contention is that performance management is too focused on individual characteristics rather than on system factors. In response to Deming's admonition, a number of scholars countered that traditional performance management practices could be customized to support quality.

In the survey conducted by Juran(1986), Walton(1989) it was found that the stronger the organizations emphasis on quality, the more prevalent will be the use of contextual work behavior performance criteria.

Blakburn\&Rosen(1993) conducted a survey on a customer-centric organization and found out that the stronger the organizations emphasis on quality, the greater the focus on competencies within the performance management system. Performance management system components that are consistent with a quality emphasis will have a stronger positive influence on performance management effectiveness in organizations with a greater quality emphasis. A quality emphasis will have stronger positive influence on organizational performance when the strategic integration of human resource management is greater.

\subsection{Components of Performance Management System}

\subsubsection{Performance Planning}

Performance planning is the first crucial component of any performance management process which forms the basis of performance appraisals. Performance planning is jointly done by theappraisee and also the reviewe in the beginning of a performance session. During this period, the employees decide upon the targets and the key performance areas which can be performed over a year within the performance budget, which is finalized after a mutual agreement between the reporting officer and the employee.

\subsubsection{Performance Appraisal and Reviewing}

The appraisals are normally performed twice in a year in an organization in the form of mid reviews and annual reviews which is held in the end of the financial year. In this process, the appraise first offers the self-filled up ratings in the self-appraisal form and also describes his/her achievements over a period of time in quantifiable terms. After the self-appraisal, the final ratings are provided by the appraiser for the quantifiable and measurable achievements of the employee being appraised

Feedback on the Performance followed by personal counseling and performance facilitation:

Feedback and counseling is given a lot of importance in the performance management process. This is the stage in which the employee acquires awareness from the appraiser about the areas of improvements and also information on whether the employee is contributing the expected levels of performance or not. The employee receives an open and a very transparent feedback and along with this the training and development needs of the employee is also identified. The appraiser adopts all the possible steps to ensure that the employee meets the expected outcomes for an organization through effective personal counseling and guidance, mentoring and representing the employee in training programmes which develop the competencies and improve the overall productivity.

\subsubsection{Rewarding good performance}

This is a very vital component as it will determine the work motivation of an employee. During this stage, an employee is publicly recognized for good performance and is rewarded. This stage is very sensitive for an employee as this may have a direct influence on the self-esteem and achievement orientation. Any contributions duly recognized by an organization helps an employee in coping up with the failures successfully and satisfies the need for affection. 


\subsubsection{Performance Improvement Plans}

In this stage, fresh set of goals are established for an employee and new deadline is provided for accomplishing those objectives. The employee is clearly communicated about the areas in which the employee is expected to improve and a stipulated deadline is also assigned within which the employee must show this improvement. This plan is jointly developed by the appraise and the appraiser and is mutually approved.

\subsubsection{Potential Appraisal}

Potential appraisal forms a basis for both lateral and vertical movement of employees. By implementing competency mapping and various assessment techniques, potential appraisal is performed. Potential appraisal provides crucial inputs for succession planning and job rotation.

Performance management is an ongoing process of identifying, measuring and developing human performance in organizations. The data which is gathered by systematic observations not only to measure current performance accurately but also to provide the necessary feedback information for changes that will improve future performance.

Ainsworth and Smith(1993) have proposed a three-step cycle: performance planning, assessment of performance, and corrective and adaptive mutual action via feedback discussions. Guinnn(1987) also proposes a three-step process: planning, managing and appraising. Torrington and Hall(1995) also proposed a model of three steps: planning, supporting and reviewing performance. The common things in all the three models is the manager and managed should have a shared view of what is expected of the employee, involvement and participation. Supporting performance is seen as a responsibility of the line manager who also has a particular part to play in reviewing performance.

Although an organization might choose to see a particular set of core activities as comprising performance management, it is important to take a systems perspective and recognize that these core activities not only interact with each other, but also with other HR activities and with various system factors that comprise the performance environment. Performance management is the area in which managers reactions have been the most researched, findings in this area indicate that the time and effort required of managers are much greater for more procedurally just systems than for more traditional systems, which have fewer opportunities for employee voice and fewer safeguards against bias.

There are many models of performance management systems. Murphy and Cleveland model have four components. One is performance judgment which is context bound, open to many biases. In performance ratings people give ratings depending on how they are used for promotion, salary increases. Next is context basing on which things the performance is being considered. In the evaluation it is concerned with the accuracy of ratings but also their communicative intent. They may be deliberately inaccurate in order to send a message to the appraise or to the organization.

Performance management system serves many different purposes. They are like improving work performance, administering merit pay, advising employees of work expectations, counseling employees, making promotion decisions, motivation employees, assessing employee potential, identifying training needs, better working relationships, helping employees set career goals, making transfer decisions, validating hiring procedures.

\subsection{Objectives of the Study}

\section{Research Design And Methodology}

- The main objective of the study is reviewing the existing Performance Management System in the IT organization

- Finding out the employee satisfaction with respect to the Performance Management System and collecting feedback from them

- Finding out what are the factors influencing the performance of the employees

- Suggesting necessary changes to the current Performance Management System

\subsection{Need of the Study}

- In the era of cut throat competition and globalization, organizations have realized the importance of strategic HR practices for gaining a competitive edge over the competitors.

- A well designed performance management system can play a crucial role in streamlining the activities of the employees in an organization for realizing the ultimate corporate mission and vision.

- Managing the performance of the employees is one of the toughest challenges which the organizations are facing today as this completely depends upon the employee's commitment, competence and clarity of performance.

- If managed efficiently through a well-planned reward practice and feedback mechanism, a performance management system can serve as an important tool for employee motivation and development. 
IV.

Data Analysis and Description Tables: Empirical Analysis

4.1 Awareness of Performance Appraisal Process in the Organization Of the total 113 respondents we enquired about the awareness of performance appraisal process in the organization (see table 4.1)

Table 4.1: Awareness of Performance Appraisal process Qf the 113 respondents 87 i.e., $76.9 \% \mathrm{know}$ how the appraisal process is being done in their organization.

\begin{tabular}{|l|l|l|}
\hline OPTION & NO OF RESPONDENTS & \% OF RESPONSE \\
\hline YES & 87 & 76.9 \\
\hline NO & 26 & 23.1 \\
\hline TOTAL & 113 & \\
\hline
\end{tabular}

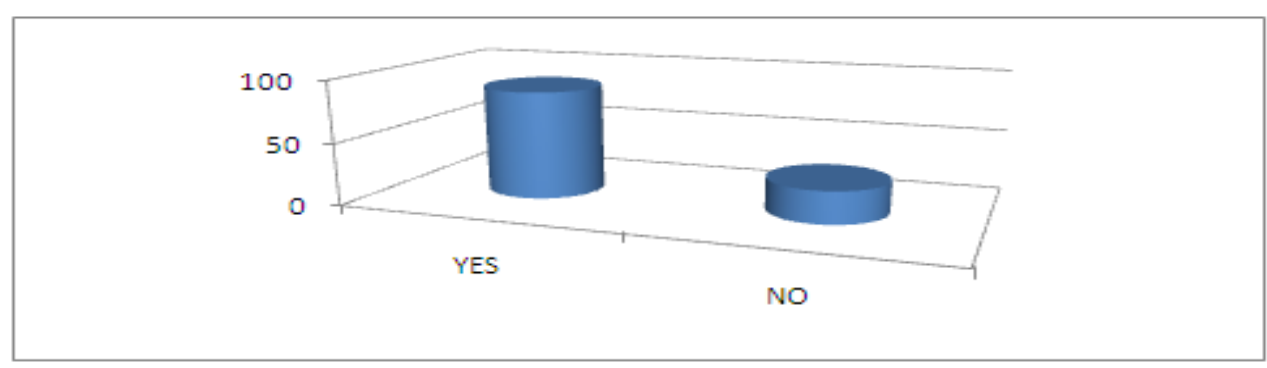

Fig 4.1: Awareness of Performance Appraisal process

The remaining 26 respondents i.e., $23.1 \%$ don't know how the performance appraisal is done in their organization (see in Fig 4.1)

\subsection{Conduction of Performance Planning}

Generally in the organization the performance planning is conducted by certain level of people. In order to know who does this certain options are given and collected responses from them and it is tabulated.

Table 4.2: Conduction of Performance Planning

\begin{tabular}{|c|c|c|}
\hline OPTION & NO OF RESPONDENTS & \% OF RESPONSE \\
\hline APPRAISE & 28 & 24.7 \\
\hline REVIEWEE & 40 & 35.39 \\
\hline BOTH & 48 & 42.47 \\
\hline TOTAL & 113 & \\
\hline
\end{tabular}

The performance planning is generally done either by appraise and sometimes by both. From the responses collected 28 respondents i.e., $24.7 \%$ says it is done by appraise.

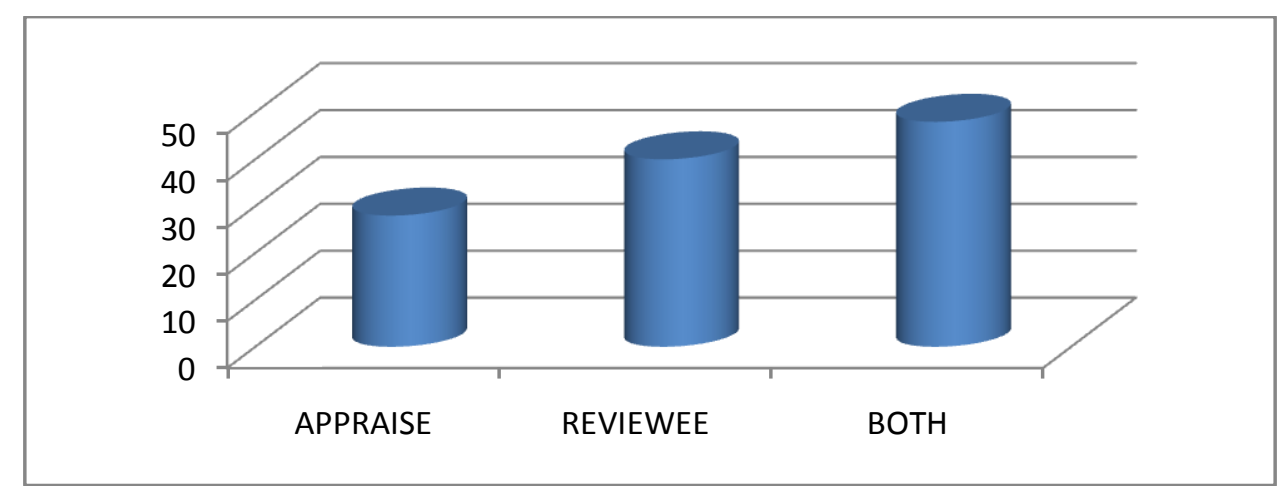

Fig 4.2: Conduction of Performance Planning 
40 respondents i.e, $35.39 \%$ says it is done by reviewee and $42.47 \%$ says it is done by both appraise and reviewee.

\subsection{Communication about Organizational goals and objectives}

In the organizations the employees are communicated about their goals and objectives in order to measure their performance and fill out the gaps.

Table 4.3: Communication about goals and objectives

\begin{tabular}{|c|c|c|}
\hline OPTION & NO OF RESPONDENTS & \% OF RESPONSE \\
\hline YES & 80 & 70.79 \\
\hline NO & 33 & 29.21 \\
\hline TOTAL & 113 & \\
\hline
\end{tabular}

The employees are given certain tasks and also time limit will be given in order to complete those tasks and these are nothing but the goals and objectives they have to achieve. 80 respondent's i.e., $70.79 \%$ had said that they are aware of their goals and objectives.

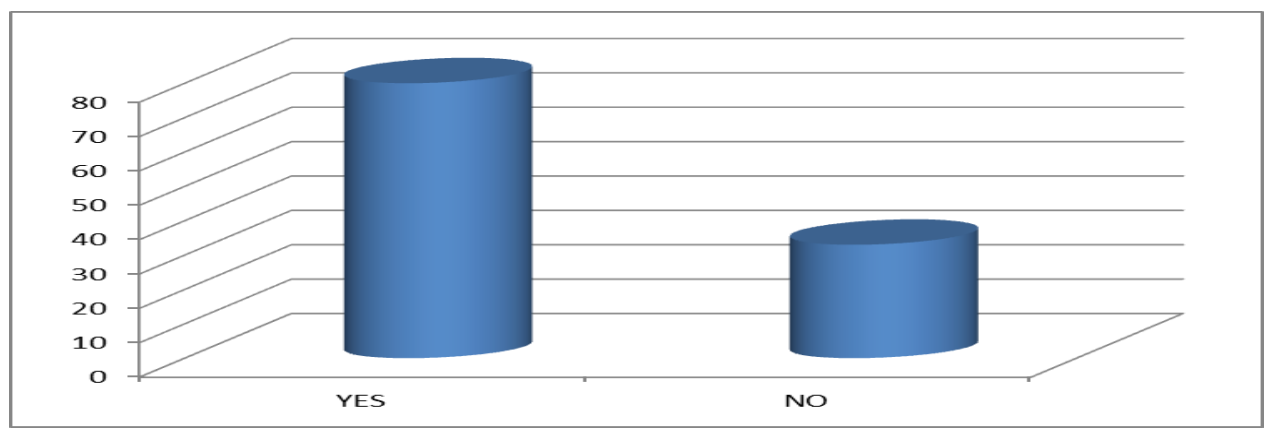

Fig 4.3:Communication about goals and objectives

\subsection{Fixation of Key Performance areas}

In the organizations there are some particular areas where they measure the performance of the employees and these areas are fixed based on some factors. 4 options are given to know how the key performance areas are fixed in the organizations.

Table 4.4: Fixation of Key Performance areas

\begin{tabular}{|l|l|l|}
\hline OPTION & NO OF RESPONDENTS & $\%$ OF RESPONSE \\
\hline $\begin{array}{l}\text { Based on organizational } \\
\text { objectives }\end{array}$ & 15 & 13.27 \\
\hline Based on departmental goals & 41 & 36.28 \\
\hline Based on individual capability & 17 & 15.04 \\
\hline $\begin{array}{l}\text { Based on team requirement } \\
\text { Based on organizational } \\
\text { objectives, departmental goals, } \\
\text { individual capability \& team } \\
\text { requirement }\end{array}$ & 16 & 14.15 \\
\hline $\begin{array}{l}\text { Based on organizational } \\
\text { objectives, departmental goals, } \\
\text { team requirement }\end{array}$ & 1 & 0.88 \\
\hline $\begin{array}{l}\text { Based on organizational } \\
\text { objectives \& individual } \\
\text { capability }\end{array}$ & 1 & 0.88 \\
\hline \begin{tabular}{l} 
TOTAI \\
\hline
\end{tabular} & 113 & 0.88 \\
\hline
\end{tabular}

15 respondents i.e., $13.27 \%$ mentioned KPA's are fixed based on organizational objectives and $36.28 \%$ had said it is based on departmental goals and $15.04 \%$ feels that it is based on individual capability. 


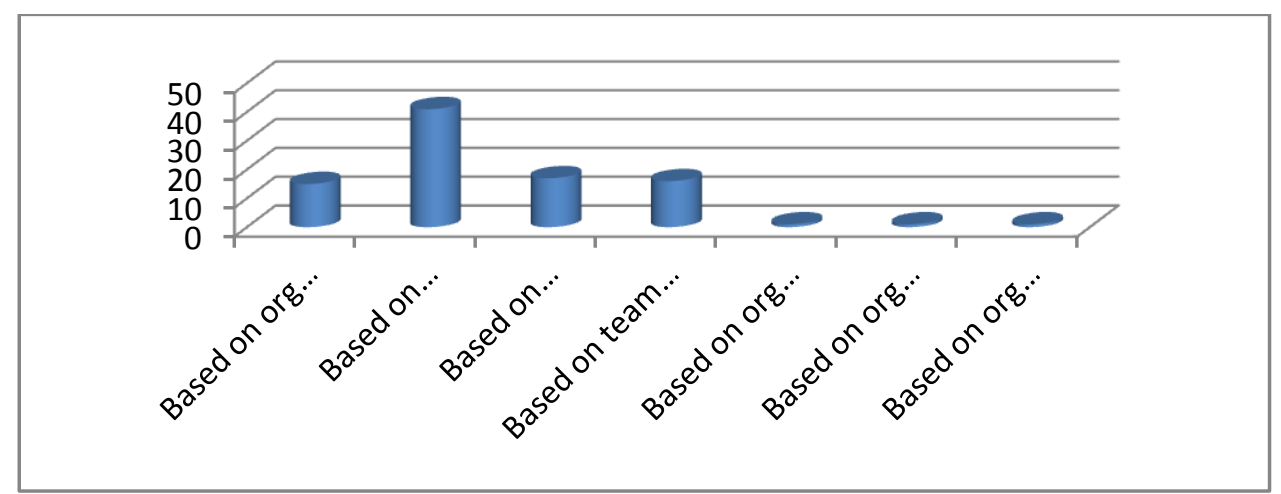

\subsection{Method of Performance review}

Fig 4.4:Fixation of Key Performance areas

Each and every organization will have their style of reviewing the performance of their employees. To know what is the style followed it had been given certain options and the results are tabulated (see in Fig 4.5)

Table 4.5: Method of Performance review

\begin{tabular}{|l|l|l|}
\hline OPTION & NO OF RESPONDENTS & $\%$ OF RESPONSE \\
\hline Self-ratings & 21 & 18.58 \\
\hline Superior's appraisal & 50 & 44.24 \\
\hline Subordinate appraisal & 11 & 9.7 \\
\hline Peer appraisal & 11 & 9.7 \\
\hline Customer appraisal & 15 & 13.27 \\
\hline 360 appraisal & 5 & 4.4 \\
\hline TOTAI & 113 & \\
\hline
\end{tabular}

$18.58 \%$ had said it is done basing on the self-ratings given by the employees, $44.24 \%$ feels that it is given based on the superior's appraisal. 9.7\% said that the review is done basing on the subordinate appraisal.

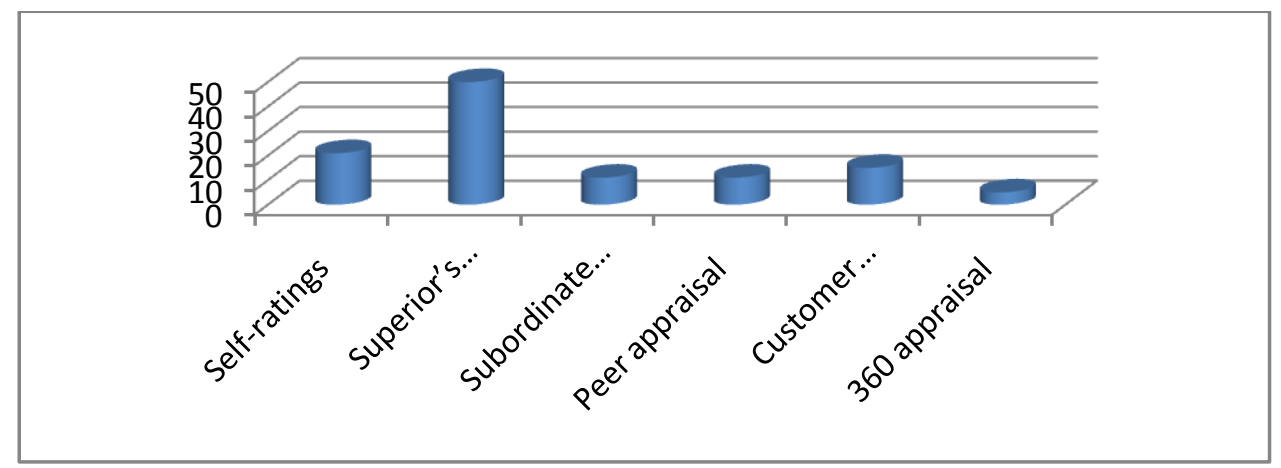

Fig 4.5: Method of Performance review

9.7\% had given that it is done based on the peer appraisal and $13.27 \%$ had said that it is done based on the customer appraisal.

\subsection{Basis for Ratings}

Generally the ratings for the employees are given basing on both the quantifiable terms and nonquantifiable terms. 


\begin{tabular}{|l|l|l|}
\hline OPTION & Table 4.6: Basis for ratings \\
\hline YES & 91 & $\%$ OF RESPONSE \\
\hline NO & & 80.53 \\
\hline TOTAI & 22 & 19.46 \\
\hline
\end{tabular}

91 respondents i.e., $80.53 \%$ had said basing on both the quantifiable and non-quantifiable terms.

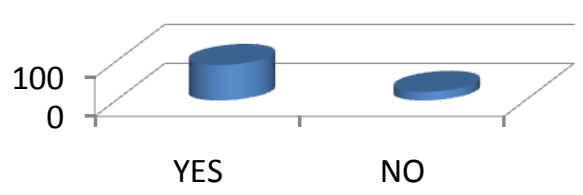

Fig 4.6: Basis for Ratings

The remaining 22 respondents i.e., $19.46 \%$ said that the ratings are not based completely on quantifiable and non-quantifiable terms.

\subsection{Rating of Self-Appraisal Forms}

There are certain parameters in the self-appraisal forms. These self-appraisal forms are useful for the employees to know where they are lagging and can be known only when they know how to rate those parameters basing on their performance.

\begin{tabular}{|l|l|l|}
\multicolumn{2}{l}{ Table 4.7:Rating of Self- Appraisal forms } \\
\hline OPTION & NO OF RESPONDENTS & $\%$ OF RESPONSE \\
\hline YES & 88 & 77.87 \\
\hline NO & & 22.12 \\
\hline TOTAI & 25 & \\
\hline
\end{tabular}

Out of 113 respondents, 88 respondents i.e., $77.87 \%$ had said that they know how to rate their performance for the parameters given in the self-appraisal forms.

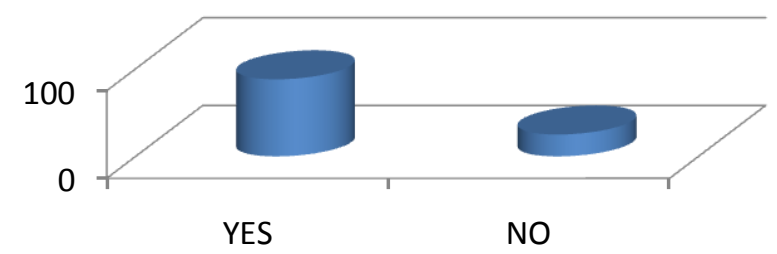

\subsection{After the Performance Review}

Fig 4.7: Rating of Self - Appraisal forms

Once the performance review is completed the appraiser meets the employees and gives suggestions, appraisal and some other things. To know what the appraiser says certain options are given and the responses are tabulated (See in Table 4.8)

\begin{tabular}{|c|c|c|}
\hline \multicolumn{2}{|c|}{ Table 4.8: After the performance review } & \% OF RESPONSE \\
\hline $\begin{array}{c}\text { OPTION } \\
\begin{array}{c}\text { Pontribution to expected } \\
\text { performance }\end{array}\end{array}$ & 45 & 39.82 \\
\hline $\begin{array}{c}\text { Open and Transparent feedback } \\
\text { Training and Developmental } \\
\text { needs }\end{array}$ & 57 & 50.44 \\
\hline TOTAI & 113 & 9.73 \\
\hline
\end{tabular}


Out of 113, 45 respondents i.e., $39.82 \%$ had said the appraiser informs them about their contribution to the expected performance. $50.44 \%$ said they receive an open and transparent feedback.

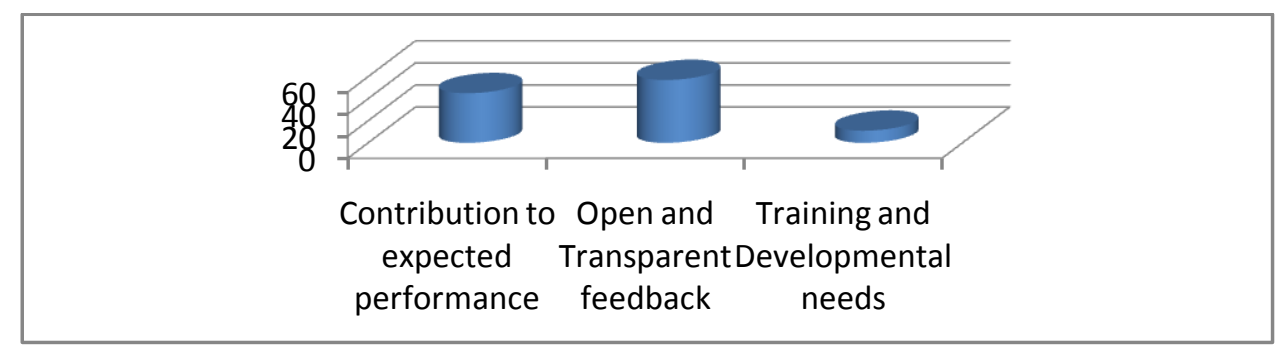

Fig 4.8: After the Performance Review

11 respondents i.e., $9.73 \%$ said that after the performance review the appraiser will find out the training and developmental needs necessary for the employees to improve their performance.

\subsection{Personal counseling and guidance}

Once the review is completed whether the employees are given personal counseling and guidance based on their performance because it is necessary to motivate the employees if their performance is not up to the mark

\begin{tabular}{|l|l|l|}
\hline \multicolumn{2}{l}{ Table 4.9: personal counseling and guidance } \\
\hline OPTION & NO OF RESPONDENTS & \% OF RESPONSE \\
\hline YES & 68 & 60.17 \\
\hline NO & 45 & 39.82 \\
\hline TOTAL & 113 & \\
\hline
\end{tabular}

It is found out that $60.17 \%$ feels that personal counseling and guidance are given once the review is done

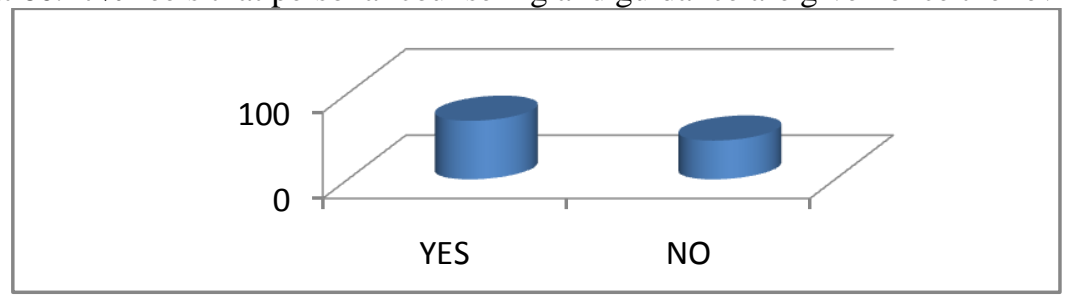

Fig 4.9:personal counseling and guidance

\subsection{Importance of Feedback and Counseling}

Feedback and counseling are one of the factors that influence the performance of the employees. So in this it is found out what is the level of the importance they give for the feedback in their organization.

Table 4.10:Importance of Feedback and Counseling

\begin{tabular}{|l|l|l|}
\hline OPTION & NO OF RESPONDENTS & \% OF RESPONSE \\
\hline YES & 75 & 66.37 \\
\hline NO & 38 & 33.62 \\
\hline TOTAL & 113 & \\
\hline
\end{tabular}

Out of 113 respondents 75 i.e., $66.37 \%$ had said that enough importance is given for the feedback and counseling in their organization. 


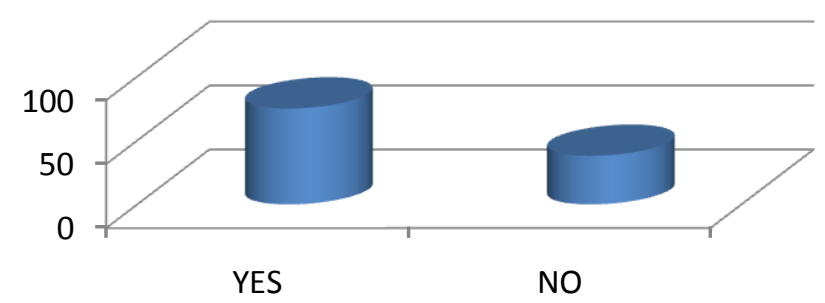

Fig 4.10: Importance of Feedback and Counseling

38 respondents i.e., $33.62 \%$ had said that the organization is not giving sufficient importance for the feedback and counseling.

\subsection{Nomination for Training Programs}

Generally in the organizations once the performance review is done the employees who are lagging they are nominated for the training programs that are conducted in the organization.

Table 4.11:Nomination for Training Programs

\begin{tabular}{|c|c|c|}
\hline OPTION & NO OF RESPONDENTS & \% OF RESPONSE \\
\hline YES & 58 & 51.32 \\
\hline NO & 55 & 48.67 \\
\hline TOTAI & 113 & \\
\hline
\end{tabular}

58 respondentsi.e., $51.32 \%$ had said that they had been nominated for the training programs in their organization after the performance review and counseling is done.

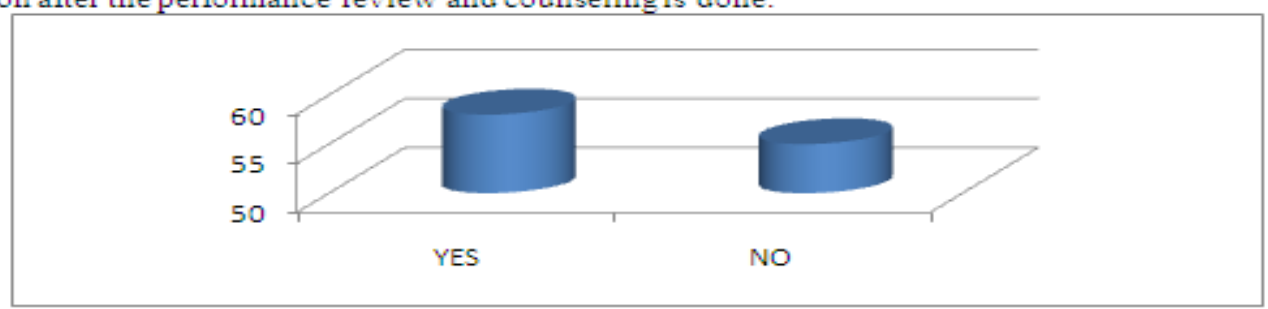

Fig 4.11: Nomination for Training Programs

55 respondents i.e., $48.67 \%$ had mentioned that organization had felt that there is no necessity for them to undergo any training sessions after their performance review and counseling is completed.

\subsection{Publicly recognized and rewarded}

When the employees perform their work effectively then at that if they are rewarded and recognized publicly then it will show a positive impact on their work and they try to do their work more effectively.

\begin{tabular}{|l|l|l|} 
Table 4.12 : Publiclix recognized and rewarded \\
\hline OPTION & NO OF RESPONDENTS & OF RESPONSE \\
\hline YES & 60 & 53.09 \\
\hline NO & 53 & 46.91 \\
\hline TOTAI & 113 & \\
\hline
\end{tabular}

Out of 113 respondents, 60 respondents i.e. $53.09 \%$ said they had been rewarded and recognized publicly in the organization

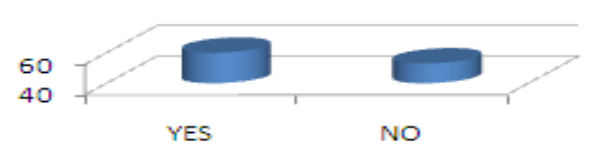

Fig 4.12: Publicly recognized and rewarded 


\subsection{Aiming at Individual Performance}

In the appraisal process is the organization is aiming at the individual performance of each and every employee or it is checking out the team performances.

Table 4.13:Aiming at individual Performance

\begin{tabular}{|l|l|l|}
\hline OPTION & NO OF RESPONDENTS & \% OF RESPONSE \\
\hline YES & 63 & 55.75 \\
\hline NO & 50 & 44.24 \\
\hline TOTAL & 113 & \\
\hline
\end{tabular}

63respondents i.e., $55.75 \%$ says that the appraisal process followed by the organization is aiming at the individual performance of the employees.

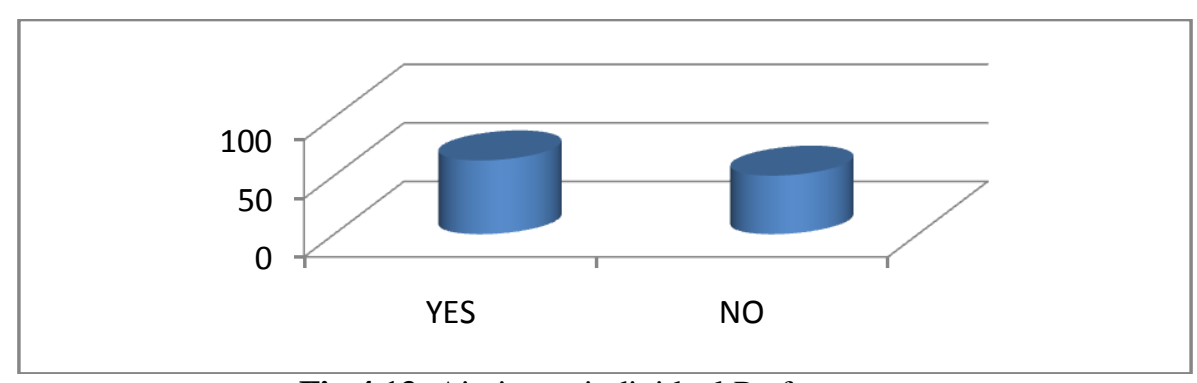

Fig 4.13: Aiming at individual Performance

\subsection{Frequency of conducting Performance Appraisal in the Organization}

The frequency of conducting the performance appraisal in the organization varies from one another. To know what the frequency on conduction in their organization is certain options are given.

TABLE 4.14 FREQUENCY OF CONDUCTING PERFORMANCE APPRAISAL IN THE ORGANIZATION

Table 4.14:Frequency of conducting Performance Appraisal in the Organization $47.78 \%$ had said that the

\begin{tabular}{|l|l|l|}
\hline OPTION & NO OF RESPONDEl process is conducted only once in their department. \\
\hline ONCE & 54 & $\%$ OF RESPONSE \\
\hline TWICE & 58 & 47.78 \\
\hline THRICE & 0 & 51.32 \\
\hline FOUR TIMES & 0 & 0 \\
\hline TOTAI & 113 & 0 \\
\hline
\end{tabular}

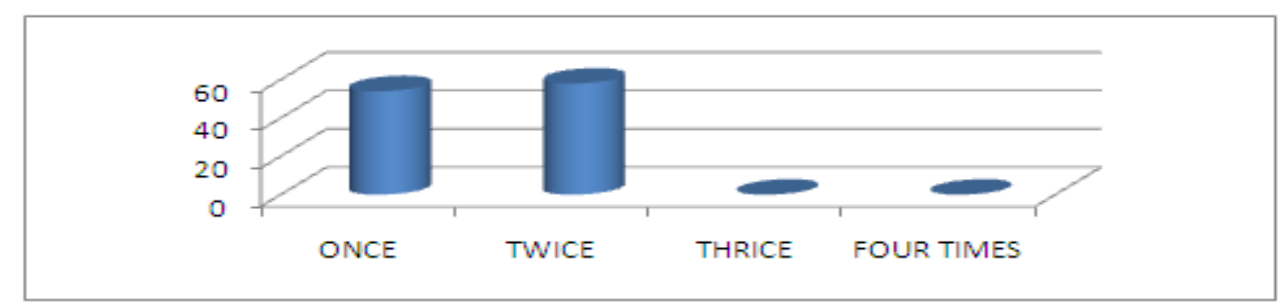

Fig 4.14: Frequency of conducting Performance Appraisal in the Organization

58 respondents i.e., $51.32 \%$ had said the performance appraisal process is conducted twice in their departments.

\subsection{Nature of Performance Management system}

Depending upon the mission, goals and objectives of the organization the organizations will develop their performance management system. 


\begin{tabular}{|l|l|l|}
\hline \multicolumn{3}{|c|}{ Table 4.15:Nature of Performance Management system } \\
\hline OPTIONS & NO OF RESPONDENTS & $\%$ OF RESPONSE \\
\hline $\begin{array}{l}\text { Helps to speed up market } \\
\text { expectations }\end{array}$ & 39 & 34.51 \\
\hline $\begin{array}{l}\text { Helps to meet businnes, } \\
\text { expectations }\end{array}$ & 42 & 37.16 \\
\hline Brings about change in attitude & 9 & 7.96 \\
\hline $\begin{array}{l}\text { Enhances operational } \\
\text { effectiveness }\end{array}$ & 23 & 20.35 \\
\hline \begin{tabular}{l} 
TOTAL \\
\hline
\end{tabular} & 113 & \\
\hline
\end{tabular}

$34.51 \%$ had said that their present performance management system helps to speed up to market expectations $37.16 \%$ mentioned it is developed to meet the business expectations.

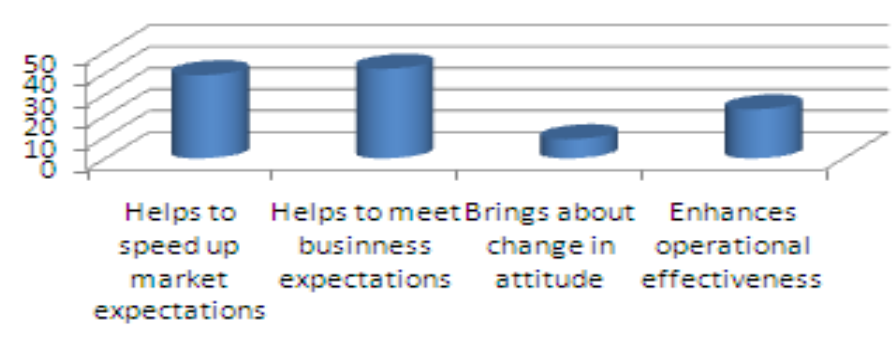

Fig 4.15: Nature of Performance Management system

$7.96 \%$ had said their performance management system is developed in such a way to bring the change in the attitude of the employees. $20.35 \%$ says their performance management system helps in increasing the operational effectiveness.

\subsection{PMS in administering Merit Pay}

By using the performance management system we can measure the performance of the employees and also it helps in administering the merit pay of the employees.

Table 4.16:PMS in administering Merit Pay

\begin{tabular}{|l|l|l|}
\hline OPTION & NO OF RESPONDENTS & \% OF RESPONSE \\
\hline YES & 73 & 64.60 \\
\hline NO & 40 & 35.40 \\
\hline TOTAL & 113 & \\
\hline
\end{tabular}

Out of 113 respondents $64.60 \%$ said their current performance management system helps them in administering the merit pay.

\subsection{PMS Linking to Promotion Decisions}

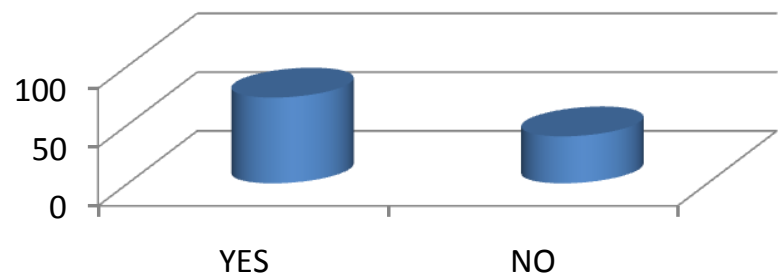

Fig 4.16: PMS in administering Merit Pay

By measuring the performance of the employees using the performance management system the promotions can be given to the employees. 
Table 4.17:PMS linking to Promotion decisions

\begin{tabular}{|l|l|l|}
\hline OPTION & NO OF RESPONDENTS & \% OF RESPONSE \\
\hline YES & 88 & 77.87 \\
\hline NO & 25 & 22.12 \\
\hline TOTA & 113 & \\
\hline
\end{tabular}

Management can take promotion decisions based on performance management system. Out of $113,77.87 \%$ said that their PMS is linked to their promotion decisions.

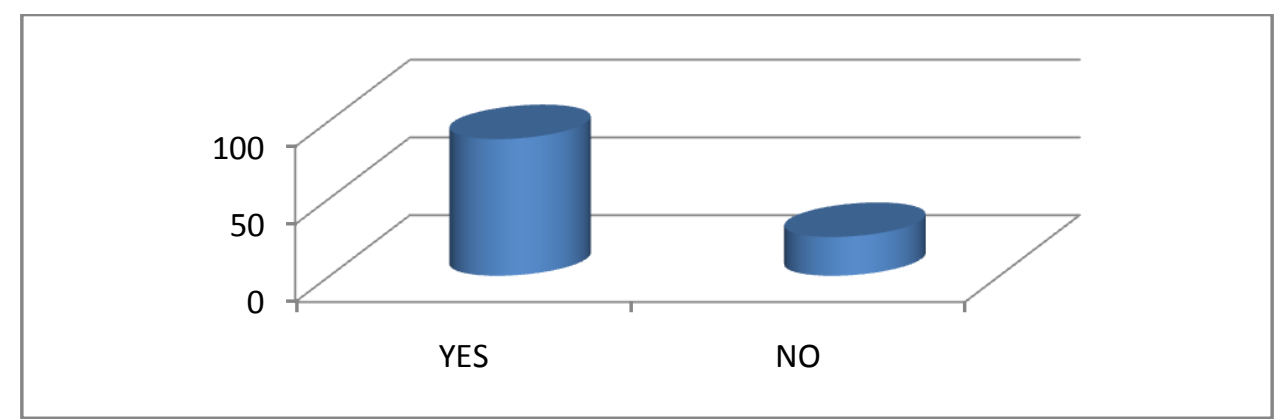

Fig 4.17: PMS linking to Promotion decisions

\subsection{Participation in Appraisal Helps in Better Working Relationships}

When employees and management together participate in the performance appraisal process sometimes it helps to develop better working relationships.

Table 4.18: Participation In Appraisal helps in better working relationships

\begin{tabular}{|l|l|l|}
\hline OPTION & NO OF RESPONDENTS & \% OF RESPONSE \\
\hline YES & 79 & 69.91 \\
\hline NO & 34 & 30.08 \\
\hline TOTAL & 113 & \\
\hline
\end{tabular}

Out of 113 respondents, $69.91 \%$ said that when employees and management work together then it automatically leads to good working relationships.

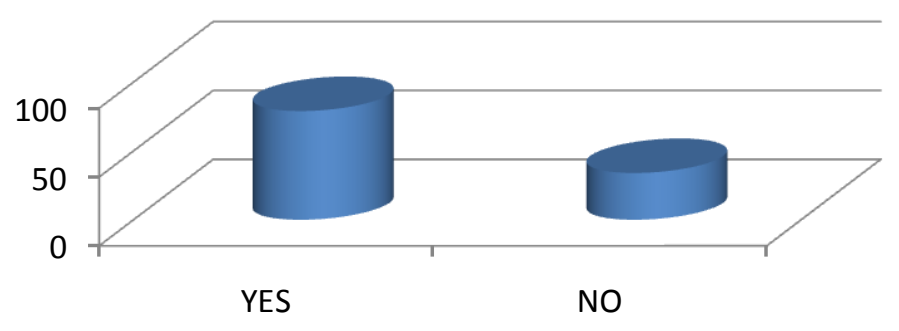

Fig 4.18: Participation In Appraisal helps in better working relationships

\subsection{Utility of PMS in Setting Career Goals}

At times basing on the performance, the employees can set their career goals and this performance can be measured by using the performance management system.

TABLE 4.19 UTILITY OF PMS IN SETTING CAREER GOALS

Table 4.19:utility of PMS in setting career goals

\begin{tabular}{|l|l|l|}
\hline OPTION & NO OF RESPONDENTS & \% OF RESPONSE \\
\hline YES & 62 & 54.86 \\
\hline NO & 51 & 45.13 \\
\hline TOTAL & 113 & \\
\hline
\end{tabular}

62 respondents, i.e., $54.86 \%$ had said that the existing performance management system had helped them in setting their career goals. 


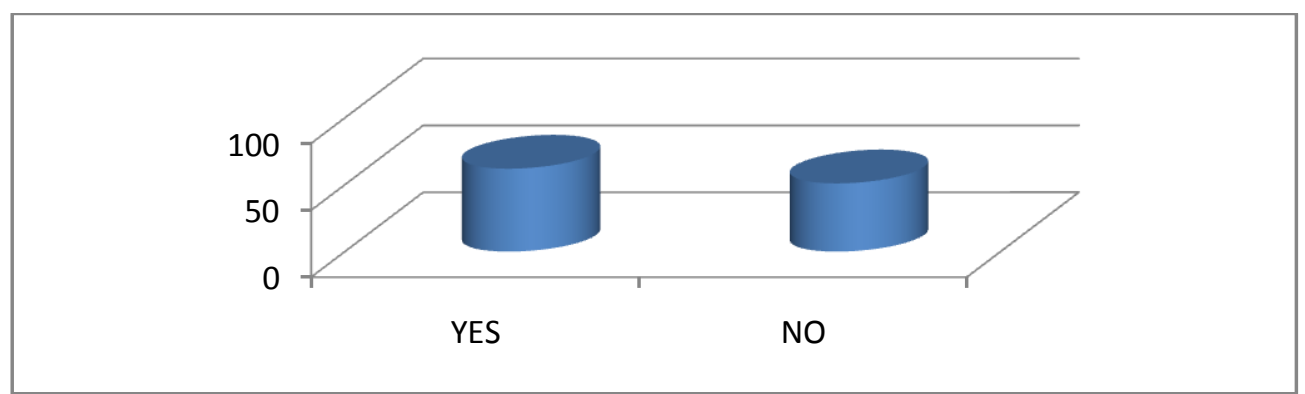

Fig 4.19: utility of PMS in setting career goals

\section{Findings And Suggestions}

$>76.9 \%$ of the respondents in the study conformed complete awareness of PAP.

$>$ A majority of $42.47 \%$ of the respondents responded that performance planning is done by both appraise and review.

$>70.79 \%$ of the respondents positively responded to the alignment of performance planning to the organizational goals and objectives.

$>$ The majority of $36.28 \%$ respondents responded that KPA's are set based on departmental goals. The other respondents varied in their responses distributed in setting up of KPA's based on organizational objectives, individual capabilities and team requirement.

$>$ From the data it appears that superior's appraisal is in practice at the movement( $44.24 \%$ respondents). Followed by self-ratings(18.58\% respondents), customer appraisal(13.27\% respondents), subordinate and peer appraisal( $9.7 \%$ respondents) and 360 appraisal( $4.4 \%$ respondents).

$>$ The findings of the study reveal that $80.53 \%$ of respondents indicate the basis for ratings are being determined in both quantifiable and non-quantifiable terms.

$>77.87 \%$ respondents revealed there awareness about parameters in the self-appraisal forms.

$>$ From the study $50.44 \%$ respondents indicated they receive open and transparent feedback from the appraiser after performance review. Followed by $39.82 \%$ respondents responded of receiving their contribution to the expected performance.

$>60.17 \%$ respondents declared that their performance review is followed by personal counseling and guidance.

$>$ From the data it is observed that feedback and counseling is given importance in the organization (66.37\% respondents).

$>51.32 \%$ respondents in the study confirmed that they are nominated for training programs based on the performance review.

$>53.09 \%$ respondents positively responded about their recognition and reward in the public.

$>$ The findings of the study reveal that $55.75 \%$ respondents responded that performance appraisal is aimed at individual performance of the employee.

$>$ From the study it is found out that $51.32 \%$ respondents responded that performance appraisal process is conducted twice in the organization.

$>37.16 \% \%$ respondents revealed their current performance management system helps to meet business expectations. Followed by $34.51 \%$ respondents responded to speed up to market expectations.

$>20.35 \%$ respondents declared that existing performance management system enhances operational effectiveness.

$>$ The findings of the study revealed that $64.60 \%$ respondents responded that performance management system in the organization helps in administering merit pay.

$>77.87 \%$ respondents revealed that performance management system is linked to promotion making decisions.

$>$ It is revealed by $69.91 \%$ respondents that participation in the performance appraisal process helps in better working relationships.

> $54.86 \%$ respondents responded that performance management system helps in setting their career goals.

\section{Conclusion}

From the study it is found out that performance management system plays a key role in the organization. From the data collected it is clear that employees in the organization are clear about how this system works. They are also aware of their goals and objectives, key performance areas and self-appraisal forms. Based on the performance calculated using this system the employees are advised for training if necessary, personal counseling and guidance are also given. This system also helps to meet business expectations and also helps to speed up to market expectations. It also helps management in making promotion 
decisions. Finally, the employees in the organization are satisfied with system which is existing and they are having the benefits of the system.

\section{References}

[1] M.Sudan Taylor, Academy of Management Journal 1998 "Managers' Reactions To Procedurally Just Performance Management Systems" vol.41 pp 568-579

[2] VictorY/.Haines, Candian Journal of Administrative Scienes 2004 " Performance Management Design And Effectiveness in Quality-Driven Organizations" vol.21 pp 146-161

[3] Dr. A.SrinivasaRao, the International Journal of Human Resource Management 2007 "Effectiveness Of Performance Management Systems" Indian School Of Business, Hyderabad

[4] Adrian Furnham, European Business Journal 2004 “Performance Management Systems ”Univesity College London, London

[5] Kostas N.Dervitsiotis, Total Quality Management "The Design of Performance Measurement Systems for Management Learning” vol.15 No.4, pp 457-473, University or Piraeus, Greece

[6] Performance Management and Appraisal Systems, T V Rao

[7] http://www.managementstudyguide.com

[8] http://www.performanceassociates.co.nz

[9] http://www.humanresources.about.com

[10] http://www.managementexchange.com

\section{Appendices}

7.1 Questionnaire on "The Study of Performance Management System in IT Organizations" Instructions: Please tick mark $(\sqrt{ })$ your choice for the questions mentioned below

- Name:

- Designation:

- Departmental affiliation:

- Year of joining the Organization

- Educational Qualification:

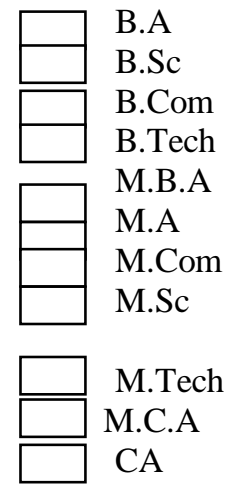

1. Are you aware of performance Appraisal process in your organization
a. YES
b. NO

2. Who does performance planning
a. Appraise
b. Reviewee
c. Both

3. Are you clearly communicated about your goals and objectives
a. YES
b. NO

4. How are the Key Performance Areas are fixed
a. Based on organizational objectives
b. Based on departmental goals/targets
c. Based on individual capability
d. Based on team requirement

5. How does performance review happen in your organization
a. Self-ratings
b. Superior's appraisal
c. Subordinate appraisal
d. Peer appraisal

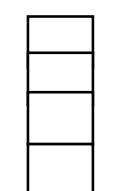


e. Customer appraisal

f. 360 appraisal

g.

6. Are the ratings based on both quantifiable terms and non-monetary terms
a. YES
b. NO
c.

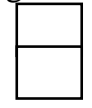

7. Do you know hay to rate your performance for the parameters given in self-appraisal forms
a. YES
b. NO

c.

8. What does the appraiser inform you after the performance review
a. Your contribution to expected performance
b. Open and Transparent feedback
c. Training and Developmental needs
d.

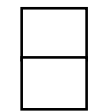

9. Is the review followed by personal counseling and guidance
a. YES
b. NO

10. Is feedback and colnseling given importance in your organization
a. YES
b. NO

11. Are you nominated for training programs after performance review and counseling
a. YES
b. NO

12. When you perform better are you publicly recognized and reward
a. YES
b. NO

13. Is the performance appraisal aimed at individual performance
a. YES
b. NO

14. How many times during the year performance appraisal process is conducted in your organization
a. Once
b. Twice
c. Thrice
d. Four times

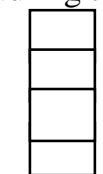

15. What is the nature of your current Performance Management System
a. Helps to speed up to market expectations
b. Helps to meet business expectations
c. Brings about change in attitude
d. Enhances operational effectiveness

16. Does the Pepfomance Management System in your organization help in administering merit pay
a. YES
b. NO

17. Is the Performance Management System linked to making promotion decisions
a. YES
b. NO

18. Does the participation in the performance appraisal process help in better working relationships
a. YES
b. NO

19. Do you find anyutility of the Performance Management System in setting your career goals
a. YES
b. NO 